\title{
Isoniazid (INH) mono-resistance and tuberculosis (TB) treatment success: analysis of European surveillance data, 2002 to 2014
}

Basel Karo ${ }^{1,2,3,4}$, Anke Kohlenberg ${ }^{4,5}$, Vahur Hollo5, Raquel Duarte ${ }^{6}$, Lena Fiebig ${ }^{3,7}$, Sarah Jackson ${ }^{8}$, Cathriona Kearns ${ }^{9}$, Csaba

Ködmön ${ }^{5}$, Maria Korzeniewska-Kosela ${ }^{10}$, Dimitrios Papaventsis ${ }^{11}$, Ivan Solovic ${ }^{12}$, Dick van Soolingen ${ }^{13}$, Marieke J. van der Werf ${ }^{5}$

1. EPIET: European Programme of Intervention Epidemiology Training, European Centre for Disease Prevention and Control, Stockholm, Sweden

2. Field Epidemiology South East \& London, National infection Service, Public Health England, London, United Kingdom

3. Infectious Disease Department, Robert Koch Institute, Berlin, Germany

4. These authors contributed equally to this article and share first authorship

5. European Centre for Disease Prevention and Control, Stockholm, Sweden

6. Directorate General of Health, Lisbon, Portugal

7. Apopo, Sokoine University of Agriculture, Morogoro, Tanzania

8. Health Protection Surveillance Centre, Dublin, Ireland

9. Public Health Agency, Belfast, Northern Ireland

10. National Tuberculosis and Lung Diseases Research Institute, Warsaw, Poland

11. National Reference Laboratory for Mycobacteria, 'Sotiria' Chest Diseases Hospital, Athens, Greece

12. National Institute for TB, Lung Diseases and Thoracic Surgery, Vysne Hagy, Catholic University Ruzomberok, Ruzomberok, Slovakia

13. Tuberculosis Reference Laboratory, National Institute for Public Health and the Environment, Bilthoven, The Netherlands

Correspondence: Anke Kohlenberg (anke.kohlenberg@ecdc.europa.eu)

Citation style for this article:

Karo Basel, Kohlenberg Anke, Hollo Vahur, Duarte Raquel, Fiebig Lena, Jackson Sarah, Kearns Cathriona, Ködmön Csaba, Korzeniewska-Kosela Maria, Papaventsis Dimitrios, Solovic Ivan, van Soolingen Dick, van der Werf Marieke J.. Isoniazid (INH) mono-resistance and tuberculosis (TB) treatment success: analysis of European surveillance data, 2002 to 2014. Euro Surveill. 2019;24(12):pii=1800392. https://doi.org/10.2807/1560-7917.ES.2019.24.12.1800392

Introduction: Isoniazid (INH) is an essential drug for tuberculosis (TB) treatment. Resistance to INH may increase the likelihood of negative treatment outcome. Aim: We aimed to determine the impact of INH mono-resistance on TB treatment outcome in the European Union/European Economic Area and to identify risk factors for unsuccessful outcome in cases with INH mono-resistant TB. Methods: In this observational study, we retrospectively analysed TB cases that were diagnosed in 2002-14 and included in the European Surveillance System (TESSy). Multilevel logistic regression models were applied to identify risk factors and correct for clustering of cases within countries. Results: A total of 187,370 susceptible and 7,578 INH mono-resistant TB cases from 24 countries were included in the outcome analysis. Treatment was successful in $74.0 \%$ of INH mono-resistant and $77.4 \%$ of susceptible TB cases. In the final model, treatment success was lower among INH mono-resistant cases (Odds ratio (OR): $0.7 ; 95 \%$ confidence interval (CI): 0.6-0.9; adjusted absolute difference in treatment success: $5.3 \%$ ). Among INH mono-resistant TB cases, unsuccessful treatment outcome was associated with age above median (OR: $1.3 ; 95 \% \mathrm{Cl}: 1.2-1.5$ ), male sex (OR: $1.3 ; 95 \% \mathrm{Cl}$ : 1.1-1.4), positive smear microscopy (OR: 1.3; 95\% Cl: 1.1-1.4), positive HIV status (OR: 3.3; 95\% CI: 1.6-6.5) and a prior TB history (OR: 1.8; $95 \%$ $\mathrm{Cl}$ : 1.5-2.2). Conclusions: This study provides evidence for an association between INH mono-resistance and a lower likelihood of TB treatment success. Increased attention should be paid to timely detection and management of INH mono-resistant TB.

\section{Introduction}

Tuberculosis (TB) causes a large degree of suffering and an estimated 1.3 million deaths per year globally, occurring mainly in less affluent countries, but also in upper-middle and high-income countries in the European Union/European Economic Area (EU/EEA) $[1,2]$. In Europe, there has been a steady decline in TB notification rates of ca $5 \%$ per year. Nevertheless, TB remains a considerable problem because of multidrugresistant (MDR) and extensively drug-resistant (XDR) TB [3].

The main public health response to the TB epidemic consists of early diagnosis, prevention of transmission and adequate treatment. In general, treatment is most successful when there is no resistance to any of the drugs designated for treatment of TB [4], and the drugs isoniazid (INH) and rifampicin (RIF) can be included in the treatment regimen. INH has long been an essential component of first-line treatment for active TB and an important drug in TB control because of its potent early bactericidal activity, low rate of adverse events and low cost [5]. Currently, there is no equivalent alternative 
Operational definitions for analysis of European

tuberculosis surveillance data, 2002-2014

The following definitions were used:

- INH mono-resistant TB cases: cases with resistance to INH and documented susceptibility to RIF, STR and EMB;

- Cases with fully drug-susceptible TB: cases with documented susceptibility to INH, RIF, STR and EMB;

- New TB cases: cases who were never previously treated for TB or who received drug treatment for less than 1 month;

- Cases with a history of TB: cases who were previously treated for TB for 1 month or more (for countries who did not report information about previous treatment, the variable previous diagnosis was used as a proxy);

- Geographical origin of cases, i.e. native vs foreign: based on the country of birth or, if this information was unavailable, on the citizenship of the patient;

- Low TB-incidence country: country with a TB incidence rate $<10$ cases per 100,000 population [31];

- High TB-incidence country: country with a TB incidence rate $\geq 10$ cases per 100,000 population [31].

EMB: ethambutol; INH: isoniazid; RIF: rifampicin; STR: streptomycin; TB: tuberculosis.

available [6]. Resistance to INH is prevalent [4], with substantial geographic variation [7].

INH mono-resistance increases the likelihood of negative treatment outcome and progression to MDR TB $[4,8,9]$. Reported treatment outcome seems to differ by setting and region for cases with INH-resistant TB [1012]. Population groups that are especially at risk of negative treatment outcome due to INH mono-resistance are children and HIV-positive patients [13-15]. Recently, two systematic reviews assessed treatment options for INH mono-resistant TB $[8,16]$. One review concluded that treatment with first-line drugs resulted in suboptimal outcome [8], whereas the other showed that extending the duration of RIF and increasing the number of effective drugs lowered the odds of unfavourable outcome [16]. An analysis of individual patient data conducted in the framework of a World Health Organization (WHO) guideline development process showed that the addition of a fluoroquinolone to a regimen of 6 months of daily RIF, ethambutol (EMB) and pyrazinamide (PZA) was associated with improved treatment success in INH-resistant cases [17]. After an evaluation of all available evidence, WHO has issued new guidelines on treatment for patients with INH mono-resistance [18]. Discussion is ongoing as to whether to maintain INH in the treatment regimen if a low degree of resistance is detected; however, there is limited data on the effect this strategy has on treatment outcome.

The European Surveillance System (TESSy), hosted by the European Centre for Disease Prevention and
Control (ECDC), contains case-based information for more than 1.5 million TB cases reported by EU/EEA countries between 1995-2015 [3]. In contrast to the information from randomised controlled trials (RCTs) and cohort studies that were included in the systematic reviews, TESSy includes information on treatment outcome obtained in a programmatic setting $[8,16]$. These data are from a larger number of patients, are more recent and are more EU/EEA-focused than the data in the aforementioned reviews. We therefore set out to analyse this dataset to determine the current treatment outcome of INH mono-resistant TB in the EU/ EEA and to identify risk factors for unsuccessful treatment outcome in cases with INH mono-resistance.

\section{Methods}

\section{Study population and data sources}

In this observational study, we retrospectively analysed TB notification data reported to the TESSy database between 2002-14. We included pulmonary and extra-pulmonary TB cases with available information on treatment outcome and drug-susceptibility testing (DST) results for at least INH, RIF, streptomycin (STR) and EMB. Information on DST for PZA was not collected in TESSy during the study period and therefore PZA was not part of our inclusion criteria.

\section{Operational definitions}

Treatment outcome was reported 12, 24 and 36 months after the start of TB treatment. We categorised treatment outcome in accordance with the 2017 joint WHO Regional Office for Europe/ECDC surveillance and monitoring report [3]. For cases with a treatment outcome of 'still on treatment' at 12 or 24 months, the final treatment outcome reported at 24 or 36 months was used, respectively. Unadjusted data was stratified by age, although this stratification was not described in the protocol for this study. The operational definitions used in this study are listed in the Box.

\section{Statistical analysis and modelling approach}

To investigate the impact of INH mono-resistant TB compared with fully drug-susceptible TB on treatment success, we applied a multilevel logistic regression model. To adjust for the heterogeneity between countries, the model was corrected with a random intercept at the country level for the differences in the average treatment success rate between countries and with a random slope for the differences in the INH monoresistance effect on the treatment success rate at the country level. The necessity of adding a random intercept and a random slope in the model was determined using the likelihood-ratio test. The main outcome was dichotomised as unsuccessful treatment (failed, died, lost to follow-up and not evaluated) vs treatment success (cured or completed), using the final reported treatment outcome. Independent variables available in the TESSy data (age, sex, geographical origin, type of TB, microscopic confirmation, history of TB, HIV status and reporting year) were also assessed as possible 


\section{FIGURE 1}

Flow chart of cases included in analysis of treatment outcome of isoniazid mono-resistant tuberculosis, 31 EU/EEA countries, 2002-2014

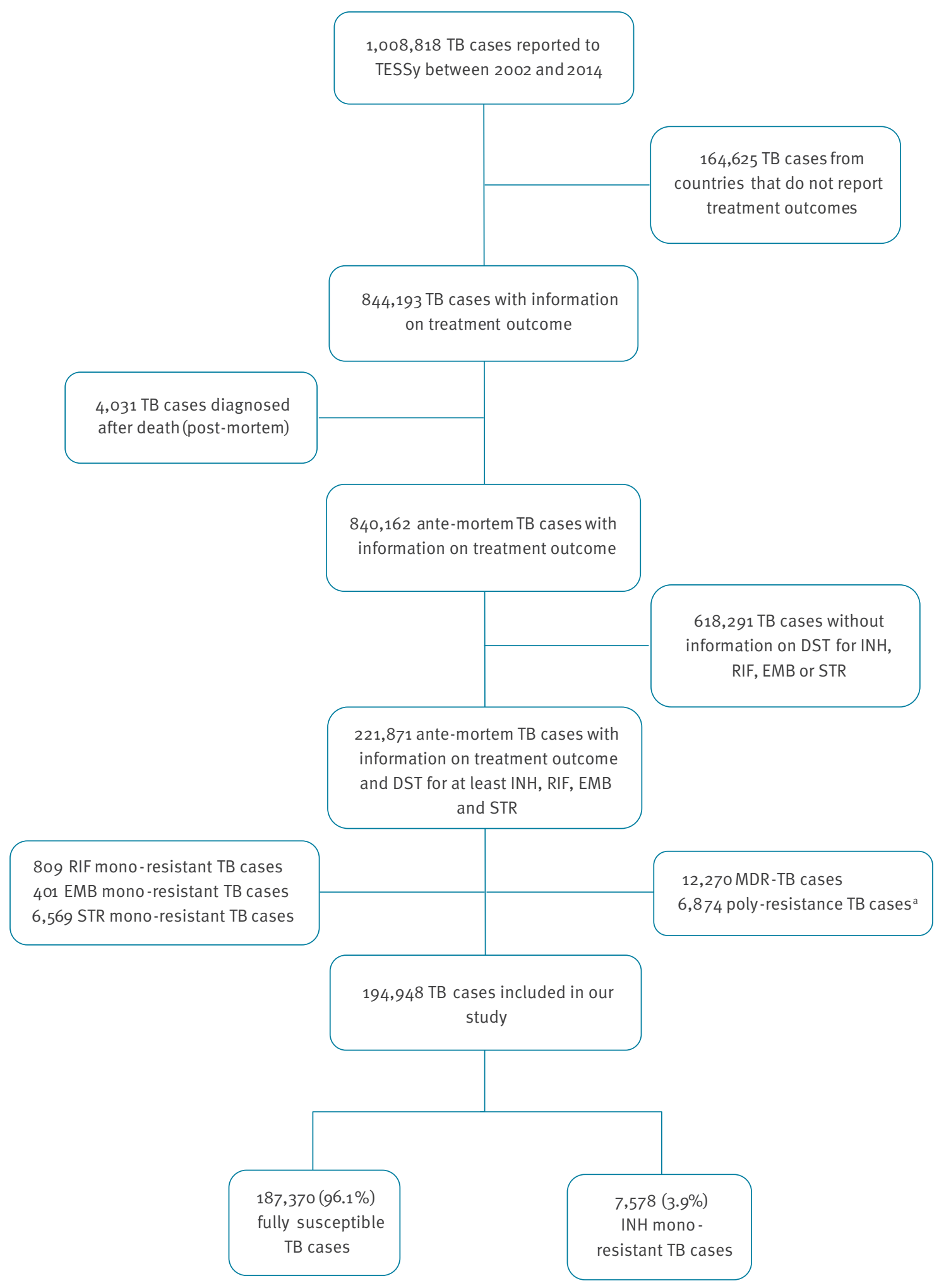

DST: drug-susceptibility testing; EMB: ethambutol; EU/EEA: European Union/European Economic Area; INH: isoniazid; MDR-TB: multidrugresistant TB; RIF: rifampicin; STR: streptomycin; TB: tuberculosis; TESSy: the European Surveillance System; WHO: World Health Organization.

${ }^{a}$ According to WHO, poly-resistance in TB cases refers to resistance to two or more first-line drugs, but not to both isoniazid and rifampicin, i.e. not MDR TB.

Data source: TESSy. 
TABLE 1

Characteristics of tuberculosis cases, by excluded and included cases, 31 EU/EEA countries, 2002-2014 $(\mathrm{n}=1,008,818)$

\begin{tabular}{|c|c|c|c|c|c|}
\hline \multirow{2}{*}{ Characteristics } & \multicolumn{2}{|c|}{ Excluded TB cases } & \multicolumn{2}{|c|}{ Included TB cases } & \multirow{2}{*}{ p value ${ }^{a}$} \\
\hline & $\mathrm{n}$ & $\%$ & $\mathrm{n}$ & $\%$ & \\
\hline Total & 813,870 & 80.7 & 194,948 & 19.3 & - \\
\hline Median age in years (IQR) & $43(30-58)$ & NA & $45(32-60)$ & NA & 0.05 \\
\hline Male sex & 522,843 & 64.3 & 127,642 & 65.5 & 0.91 \\
\hline Cases of foreign origin & 172,776 & 22.4 & 56,451 & 29.3 & 0.51 \\
\hline Extra-pulmonary TB & 177,592 & 21.9 & 28,032 & 14.4 & 0.11 \\
\hline New TB cases & 638,026 & 78.4 & 163,546 & 83.9 & 0.02 \\
\hline Microscopic confirmation & 296,127 & 48.3 & 93,560 & 61.2 & $<0.01$ \\
\hline Positive HIV status & 4,976 & 0.6 & 1,248 & 0.6 & 0.68 \\
\hline \multicolumn{6}{|c|}{ Proportion of cases by reporting countries } \\
\hline Austria & 4,771 & 44.6 & 5,919 & 55.4 & \multirow{31}{*}{$p<0.01$} \\
\hline Belgium $^{b}$ & 13,830 & 100 & 0 & 0 & \\
\hline Bulgaria & 14,542 & 71.9 & 5,695 & 28.1 & \\
\hline Croatia & 619 & 38.9 & 972 & 61.1 & \\
\hline Cyprus & 328 & 57.3 & 244 & 42.7 & \\
\hline Czech Republic & 4,927 & 46.4 & 5,704 & 53.7 & \\
\hline Denmark & 4,086 & 82.9 & 843 & 17.1 & \\
\hline Estonia & 2,927 & 50.9 & 2,826 & 49.1 & \\
\hline Finland & 2,577 & 58.7 & 1,817 & 41.3 & \\
\hline France $^{c}$ & 70,140 & 100 & 0 & 0 & \\
\hline Germany & 28,524 & 41.6 & 40,015 & 58.4 & \\
\hline Greece $^{\mathrm{d}}$ & 7,911 & 100 & 0 & 0 & \\
\hline Hungary & 17,720 & 78.4 & 4,879 & 21.6 & \\
\hline Iceland & 137 & 97.8 & 3 & 2.2 & \\
\hline Ireland & 3,660 & 67.0 & 1,803 & 33.0 & \\
\hline Italyc & 56,146 & 100 & 0 & 0 & \\
\hline Latvia & 7,533 & 47.8 & 8,209 & 52.2 & \\
\hline Liechtenstein $^{d}$ & 5 & 100 & 0 & 0 & \\
\hline Lithuania & 13,572 & 51.9 & 12,570 & 48.1 & \\
\hline Luxembourgd & 443 & 100 & 0 & 0 & \\
\hline Malta & 305 & 68.9 & 138 & 31.2 & \\
\hline Netherlands & 8,314 & 59.0 & 5,769 & 41.0 & \\
\hline Norway & 1,450 & 34.4 & 2,771 & 65.6 & \\
\hline Poland & 70,917 & 64.3 & 39,430 & 35.7 & \\
\hline Portugal & 24,906 & 60.5 & 16,241 & 39.5 & \\
\hline Romania & 311,991 & 98.9 & 3,265 & 1.1 & \\
\hline Slovenia & 432 & 15.4 & 2,372 & 84.6 & \\
\hline Slovakia & 4,189 & 52.6 & 3,783 & 47.4 & \\
\hline Spain ${ }^{c}$ & 54,232 & 100 & 0 & 0 & \\
\hline Sweden & 5,881 & 82.3 & 1,264 & 17.7 & \\
\hline UK & 76,855 & 73.0 & 28,416 & 27.0 & \\
\hline
\end{tabular}

EU/EEA: European Union/European Economic Area; HIV: human immunodeficiency virus; IQR: interquartile range; TB: tuberculosis; TESSy: The European Surveillance System; UK: United Kingdom.

${ }^{a}$ Obtained by a multivariable logistic regression model corrected for clustering within countries.

${ }^{\text {b }}$ Not performing drug susceptibility testing for streptomycin.

${ }^{\mathrm{c}}$ Not reporting case-based drug susceptibility data and treatment outcome data.

${ }^{\mathrm{d}}$ Not reporting treatment outcome data.

Data source: TESSy. 
TABLE 2A

Characteristics of tuberculosis cases by isoniazid mono-resistance status, 24 EU/EEA countries, 2002-2014 (n = 194,948)

\begin{tabular}{|c|c|c|c|c|}
\hline \multirow[t]{2}{*}{ Characteristics } & \multicolumn{2}{|c|}{$\begin{array}{l}\text { Fully susceptible } \\
\text { TB cases }\end{array}$} & \multicolumn{2}{|c|}{$\begin{array}{c}\text { INH mono-resistant } \\
\text { TB cases }\end{array}$} \\
\hline & $\mathrm{n}$ & $\%$ & $\mathrm{n}$ & $\%$ \\
\hline Total & 187,370 & NA & 7,578 & NA \\
\hline \multicolumn{5}{|l|}{ Sex } \\
\hline Female & 64,640 & 34.5 & 2,566 & 33.8 \\
\hline Male & 122,636 & 65.4 & 5,006 & 66.1 \\
\hline Unknown & 94 & 0.1 & 6 & 0.1 \\
\hline \multicolumn{5}{|l|}{ Age (years) } \\
\hline Median (IQR) & $46(32-60)$ & NA & $41(30-54)$ & NA \\
\hline \multicolumn{5}{|l|}{ Age group } \\
\hline$<15$ & 3,160 & 1.7 & 174 & 2.3 \\
\hline $15-44$ & 89,845 & 47.9 & 4,346 & 57.3 \\
\hline $45-64$ & 57,172 & 30.5 & 2,202 & 29.0 \\
\hline$>64$ & 37,127 & 19.8 & 855 & 11.3 \\
\hline Unknown & 66 & 0.1 & 1 & 0.1 \\
\hline \multicolumn{5}{|l|}{ Geographical origin } \\
\hline Native & 131,344 & 70.1 & 4,639 & 61.2 \\
\hline Foreign & 53,648 & 28.6 & 2,803 & 37.0 \\
\hline Unknown & 2,378 & 1.3 & 136 & 1.8 \\
\hline \multicolumn{5}{|l|}{ Type of TB } \\
\hline Pulmonary & 160,231 & 85.5 & 6,341 & 83.7 \\
\hline Extra-pulmonary & 26,813 & $14 \cdot 3$ & 1,219 & 16.1 \\
\hline Unknown & 326 & 0.2 & 18 & 0.2 \\
\hline \multicolumn{5}{|l|}{ Sputum smear microscopy } \\
\hline Negative & 57,063 & 30.4 & 2,183 & 28.8 \\
\hline Positive & 89,898 & 47.9 & 3,662 & 48.3 \\
\hline Unknown & 40,409 & 21.7 & 1,733 & 22.9 \\
\hline \multicolumn{5}{|l|}{ History of TB } \\
\hline New TB case & 157,526 & 84.1 & 6,020 & 79.4 \\
\hline Case with history of TB & 17,634 & 9.4 & 1,027 & 13.6 \\
\hline Case with unknown TB history & 12,210 & 6.5 & 531 & 7.0 \\
\hline \multicolumn{5}{|l|}{ HIV status } \\
\hline Negative & 17,624 & 9.4 & 823 & 10.9 \\
\hline Positive & 1,203 & 0.6 & 45 & 0.6 \\
\hline Unknown & 168,543 & 90.0 & 6,710 & 88.5 \\
\hline \multicolumn{5}{|l|}{ EU/EEA countries } \\
\hline Low TB incidence & 74,742 & 40.0 & 2,582 & 34.1 \\
\hline High TB incidence $^{b}$ & 112,628 & 60.0 & 4,996 & 65.9 \\
\hline \multicolumn{5}{|l|}{ Reporting years } \\
\hline $2002-2005$ & 49,532 & 26.4 & 2,089 & 27.6 \\
\hline 2006-2009 & 61,478 & 32.8 & 2,403 & 31.8 \\
\hline $2010-2014$ & 76,360 & 40.8 & 3,086 & 40.6 \\
\hline
\end{tabular}

EU/EEA: European Union/European Economic Area; INH: isoniazid; IQR: interquartile range; NA: not applicable; TB: tuberculosis; TESSy: The European Surveillance System; UK: United Kingdom.

a TB cases susceptible to at least isoniazid, rifampicin, ethambutol and streptomycin.

${ }^{\mathrm{b}} \mathrm{High}$-incidence countries were defined as those with 10 or more TB cases per 100,000 population in 2015 (Bulgaria, Croatia, Estonia, Latvia, Lithuania, Poland, Portugal, Romania and the UK).

Data source: TESSy. 
TABLE 2B

Characteristics of tuberculosis cases by isoniazid mono-resistance status, 24 EU/EEA countries, 2002-2014 (n = 194,948)

\begin{tabular}{|c|c|c|c|c|}
\hline \multirow[t]{2}{*}{ Characteristics } & \multicolumn{2}{|c|}{$\begin{array}{c}\text { Fully susceptible } \\
\text { TB cases }{ }^{\mathrm{a}}\end{array}$} & \multicolumn{2}{|c|}{$\begin{array}{l}\text { INH mono-resistant } \\
\text { TB cases }\end{array}$} \\
\hline & $\mathrm{n}$ & $\%$ & $\mathrm{n}$ & $\%$ \\
\hline \multicolumn{5}{|c|}{ Number of TB cases by reporting country } \\
\hline Austria & 5,716 & 96.6 & 203 & 3.4 \\
\hline Bulgaria & 5,416 & 95.1 & 279 & 4.9 \\
\hline Croatia & 953 & 98.0 & 19 & 2.0 \\
\hline Cyprus & 224 & 91.8 & 20 & 8.2 \\
\hline Czech Republic & 5,626 & 98.6 & 78 & 1.4 \\
\hline Denmark & 807 & 95.7 & 36 & $4 \cdot 3$ \\
\hline Estonia & 2,721 & 96.3 & 105 & 3.7 \\
\hline Finland & 1,759 & 96.8 & 58 & 3.2 \\
\hline Germany & 38,700 & 96.7 & 1,315 & 3.3 \\
\hline Hungary & 4,663 & 95.6 & 216 & 4.4 \\
\hline Iceland & 1 & 33.3 & 2 & 66.7 \\
\hline Ireland & 1,725 & 95.7 & 78 & 4.3 \\
\hline Latvia & 7,648 & 93.1 & 561 & 7.4 \\
\hline Lithuania & 11,790 & 93.8 & 780 & 6.2 \\
\hline Malta & 136 & 98.5 & 2 & 1.5 \\
\hline Netherlands & 5,508 & 95.5 & 261 & 4.5 \\
\hline Norway & 2,630 & 94.9 & 141 & 5.1 \\
\hline Poland & 38,579 & 97.8 & 851 & 2.2 \\
\hline Portugal & 15,764 & 97.1 & 477 & 2.9 \\
\hline Romania & 3,032 & 92.9 & 233 & 7.1 \\
\hline Slovenia & 2,346 & 98.9 & 26 & 1.1 \\
\hline Slovakia & 3,697 & 97.7 & 86 & 2.3 \\
\hline Sweden & 1,204 & 95.3 & 60 & 4.7 \\
\hline UK & 26,725 & 94.1 & 1,691 & 5.6 \\
\hline \multicolumn{5}{|c|}{ Final treatment outcome } \\
\hline Treatment success & 144,961 & 77.4 & 5,611 & 74.0 \\
\hline Death & 14,681 & 7.8 & 516 & 6.8 \\
\hline Failed & 1,111 & 0.6 & 102 & 1.4 \\
\hline Lost to follow-up & 10,259 & 5.5 & 567 & 7.5 \\
\hline Not evaluated & 16,358 & 8.7 & 782 & 10.3 \\
\hline
\end{tabular}

EU/EEA: European Union/European Economic Area; INH: isoniazid; TB: tuberculosis; TESSy: The European Surveillance System; UK: United Kingdom.

${ }^{a}$ TB cases susceptible to at least isoniazid, rifampicin, ethambutol and streptomycin.

${ }^{b}$ Seven countries (Belgium, France, Greece, Italy, Liechtenstein, Luxembourg and Spain) were excluded from this study, as they did not report treatment outcome and/or the required susceptibility data.

Data source: TESSy.

confounders in the relationship between INH monoresistant TB and treatment success. Independent variables that caused a change in the regression coefficient between INH mono-resistant TB and treatment success of $>10 \%$ were considered potential confounders and were retained in the final multilevel multivariable model. In addition, we evaluated the interaction of INH mono-resistant TB with age and history of TB on treatment success at a $p$ value of 0.1. Furthermore, a sensitivity analysis was conducted to assess the impact of INH mono-resistance after excluding cases with the outcome 'not evaluated'.

To identify risk factors for an unsuccessful treatment outcome in INH mono-resistant cases, the multilevel univariate and multivariable logistic regression models were used to examine the association between predicting variables (age, sex, geographical origin, microscopy confirmation, history of TB, HIV status, type of TB and reporting year) and unsuccessful treatment outcome. Age was dichotomised into $<$ and $\geq$ the median age of 
Treatment outcome of tuberculosis, by isoniazid mono-resistance status, 24 EU/EEA countries, 2002-2014 $(\mathrm{n}=194,948)$

A. Treatment outcome at 12 months

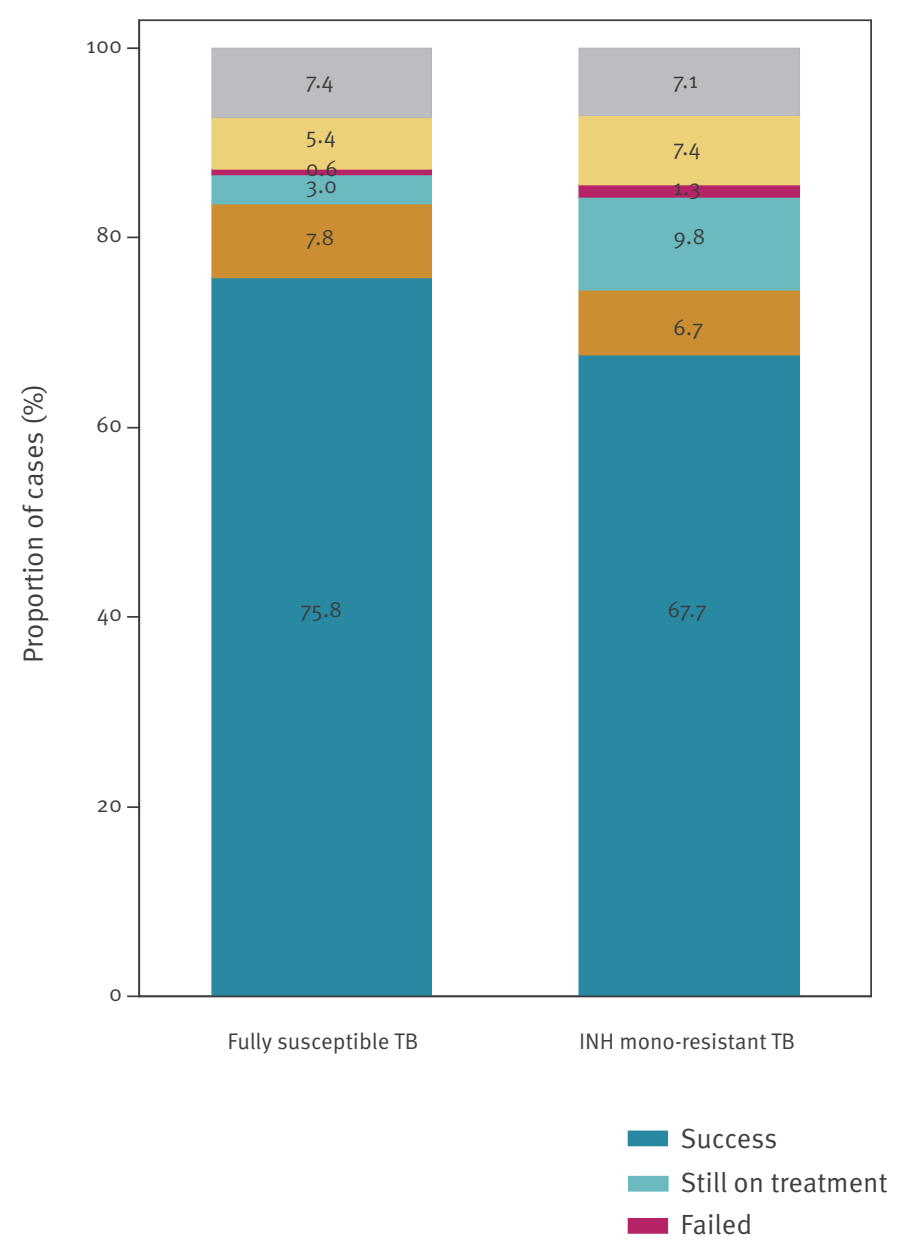

B. Final reported treatment outcome

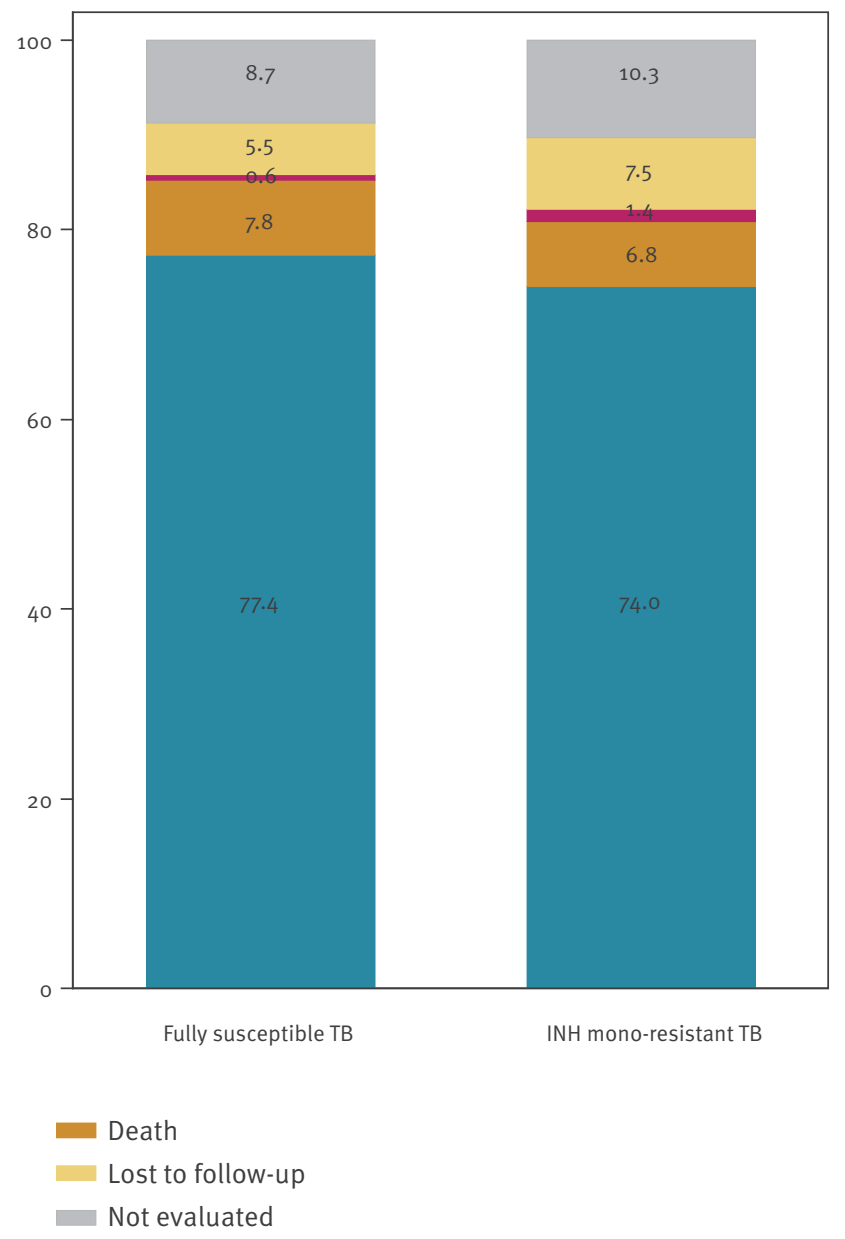

EU/EEA: European Union/European Economic Area; INH: isoniazid; TESSy: The European Surveillance System.

a Treatment outcome at 12 months.

${ }^{\mathrm{b}}$ Final reported treatment outcome.

Data source: TESSy.

the included study population. In a sensitivity analysis, cases with the outcome 'not evaluated' were excluded. As the outcomes were proportions, we used logistic regression for all models. Odds ratios (OR) with 95\% confidence intervals $(\mathrm{Cl})$ were calculated to assess the strength of the association. All analyses were performed using the STATA (Stata/SE 14.1, StataCorp LP, Texas, United States (US)) software.

\section{Ethical statement}

This study is based on data collected on the basis of statutory notification in each EU/EEA country and reported anonymously to ECDC on the basis of decision No 2119/98/EC of the European Parliament and of the
Council [19]. Therefore, informed consent from patients is not required.

\section{Results}

Characteristics of the study population

From 2002-14, a total of 1,008,818 TB cases were notified in 31 EU/EEA countries and reported to TESSy. TB cases without reported treatment outcome for the years 2002-14 $(n=164,625)$ or who were diagnosed postmortem $(n=4,031)$ were excluded from our analysis. We also excluded 618,291 TB cases without DST results for INH, RIF, EMB or STR. Furthermore, we excluded cases with drug resistance other than INH mono-resistance $(n=26,923)$. The remaining 194,948 TB cases from 24 
EU/EEA countries fulfilled the inclusion criteria and were therefore eligible for our analysis. Of them, 7,578 (3.9\%) were cases with INH mono-resistant TB (Figure 1). Differences in the characteristics of included and excluded cases are presented in Table 1 . No change in the proportion of INH mono-resistant TB was observed during the study period (Trend analyses: $p$ value $=0.30$ ). The majority of included cases were reported by Germany, Poland and the United Kingdom (UK) (20.5\%, $20.2 \%$ and $14.6 \%$, respectively). Cases with INH monoresistant TB were more likely to be younger than cases with fully drug-susceptible TB (median age 41 vs 46 years), be of foreign origin (37.0\% vs $28.6 \%$ ) and have a prior history of TB (13.6\% vs $9.4 \%$ ). Cases with INH mono-resistant TB were also more frequently reported by high TB-incidence countries, compared with low TB-incidence countries (65.9\% vs 60.0\%) (Table 2 ).

\section{Tuberculosis treatment outcome}

At 12 months after the start of treatment, INH monoresistant TB cases had a lower TB treatment success rate than cases with fully susceptible TB $(67.7 \%$ $(5,131 / 7,578)$ vs $75.8 \%(142,051 / 187,370))$. Noticeably, a higher proportion of cases 'still on treatment' was observed among INH mono-resistant TB cases in comparison to fully susceptible TB cases $(9.8 \%(745 / 7,578)$ vs $3.0 \%(5,651 / 187,370)$, respectively). The treatment success rate was still lower in INH mono-resistant TB cases compared with fully susceptible TB cases (74.0\% vs $77.4 \%$ ), when assessing the final reported treatment outcome (Table 2). Fewer INH mono-resistant cases died while being treated for TB, compared with fully susceptible TB cases $(6.8 \%$ vs $7.8 \%)$ (Table 2). However, a higher proportion of cases with treatment failure was observed among INH mono-resistant TB cases in comparison to fully susceptible TB cases (1.4\% vs $0.6 \%$, respectively) (Table 2 ). Unknown treatment outcome (i.e. lost to follow-up and not evaluated) was documented for $17.8 \%$ of INH mono-resistant TB cases vs $14.2 \%$ of fully susceptible TB cases (Table 2, Figure 2).

For cases younger than the median age of 45 years, the final treatment success rates were $76.6 \%(3,341 / 4,362)$ for INH mono-resistant TB and 82.6\% $(73,960 / 89,536)$ for susceptible TB. For cases aged $\geq 45$ years, the treatment success rate decreased for both case groups; however, the difference was smaller $(70.6 \%$ $(2,270 / 3,216)$ for INH mono-resistant TB vs $72.6 \%$ $(71,001 / 97,834)$ for fully susceptible TB). Treatment outcome by age group and INH mono-resistance status are presented in Figure 3a. The treatment success rate varied between countries for both fully susceptible and INH mono-resistant TB cases. Markedly, a relatively high proportion of deaths during TB treatment was reported among INH mono-resistant TB cases in Croatia (21.1\%) and Slovenia (19.2\%). In Romania and Hungary, a high proportion of cases with treatment failure was observed ( $12.0 \%$ and $10.2 \%$, respectively) (Figure $3 b$ ).
Impact of INH mono-resistance on tuberculosis treatment success

In the univariate model corrected for clustering within countries, INH mono-resistance was associated with a lower TB treatment success compared with cases with fully susceptible TB (OR: 0.8; 95\% Cl: 0.7-0.9). Out of all statistically evaluated covariates, adding age, microscopic confirmation or history of TB to the crude model led to the predefined change $(>10 \%)$ in the regression coefficient for INH mono-resistance and, therefore, these covariates were retained in the multivariable model as potential confounders. No interactions of INH mono-resistant TB with age ( $p$ value $=0.9)$ or history of TB treatment ( $p$ value $=0.2$ ) were observed; therefore, these variables were not included in the final model.

In the final multivariable model, treatment success among INH mono-resistant TB was lower compared with fully drug-susceptible TB (adjusted OR: 0.7; 95\% $\mathrm{Cl}$ : 0.6-0.9). This corresponds to an adjusted treatment success of $74.0 \%$ for INH mono-resistant TB and $79.3 \%$ for fully susceptible TB, adjusted absolute difference of $5.3 \%$ (Supplementary Table S1). The treatment success remained lower among INH mono-resistant TB compared with fully susceptible TB in the multivariable model after excluding cases with 'not evaluated' as treatment outcome (OR: 0.7; 95\% Cl: 0.6-0.8) (data not shown).

\section{Factors associated with unsuccessful final} treatment outcome of INH mono-resistant tuberculosis cases

In the multivariable model adjusted for heterogeneity between countries, unsuccessful treatment among INH mono-resistant TB cases was associated with age $\geq$ median age (41 years) (OR: $1.3 ; 95 \% \mathrm{Cl}: 1.2-1.5$ ), male sex (OR: 1.3 95\%; Cl: 1.1-1.4), positive microscopy (OR: $1.3 ; 95 \% \mathrm{Cl}: 1.1-1.4$ ), history of TB (OR: $1.8 ; 95 \%$ $\mathrm{Cl}: 1.5-2.2)$ and positive HIV status (OR: $3.3 ; 95 \% \mathrm{Cl}$ : 1.6-6.5) (Figure 4) (Supplementary Table S2). In the sensitivity analysis, excluding cases with the treatment outcome 'not evaluated', no change in the associated risk factors was observed (data not shown).

INH mono-resistant and fully susceptible TB shared the same risk factors for unsuccessful treatment, except for being of foreign origin, which was associated with a higher risk for unsuccessful treatment in fully susceptible but not INH mono-resistant TB cases in the multivariable model (data not shown).

\section{Discussion}

Our retrospective study of European surveillance data, including 7,578 cases of INH mono-resistant TB and 187,370 cases of fully susceptible TB, shows that INH mono-resistance is associated with lower TB treatment success in the final TB treatment outcome. This association between INH mono-resistance and lower treatment success is in line with a previous systematic review [20]. Although this review was published in 2009, it includes many studies that were published 


\section{FIGURE 3}

Treatment outcome of tuberculosis by isoniazid mono-resistance status and (A) age group a and (B) reporting country, 24 EU/EEA countries, 2002-2014 $(\mathrm{n}=194,948)$
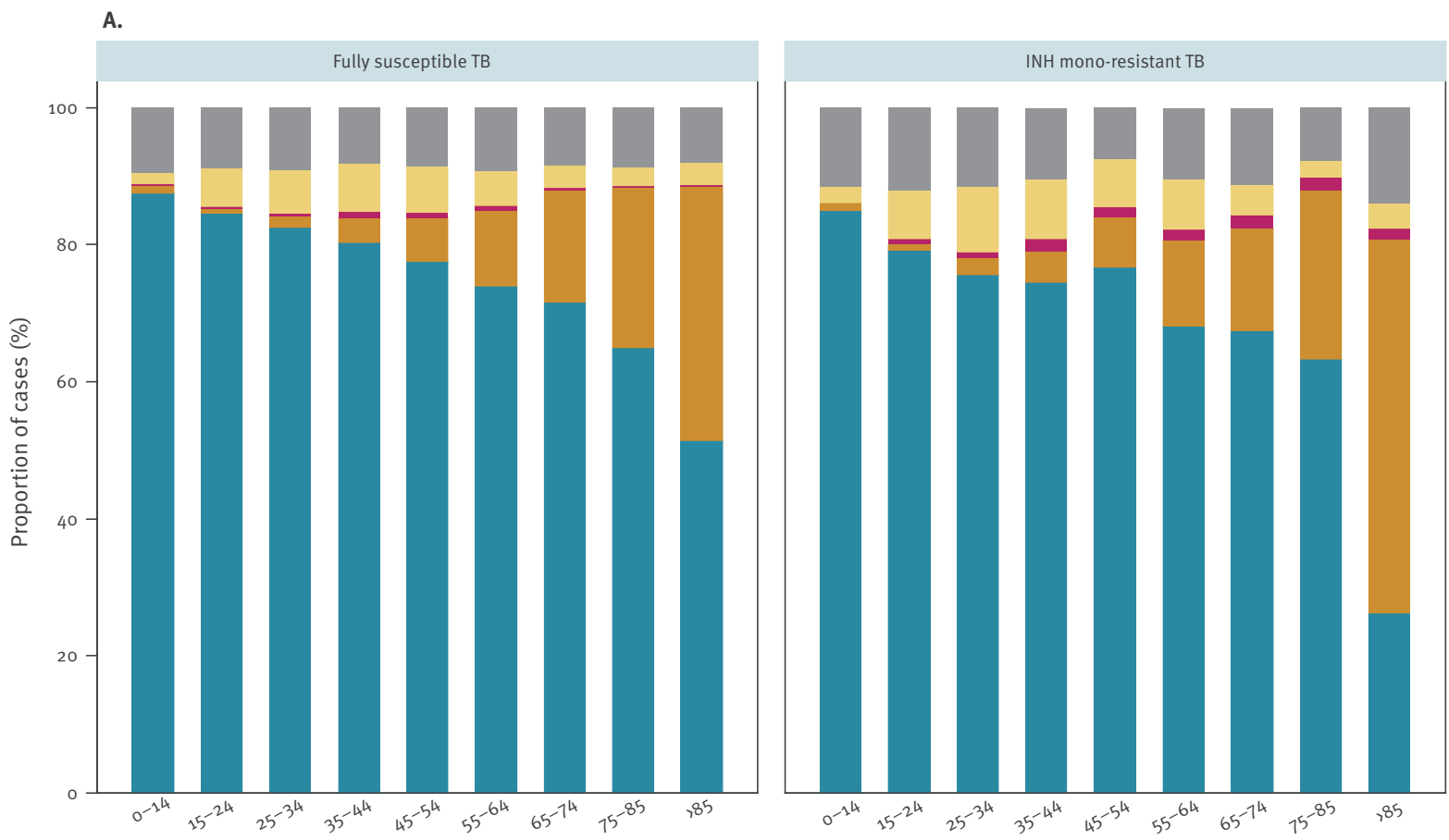

Age group in years

B.

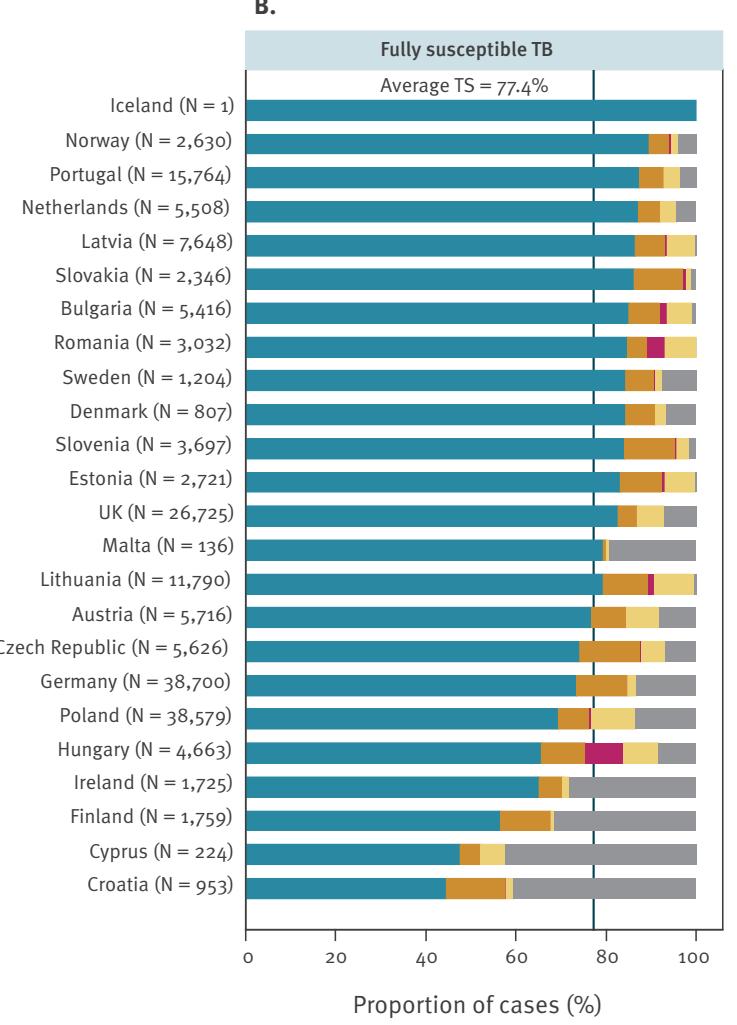

Success
Lost to follow-up

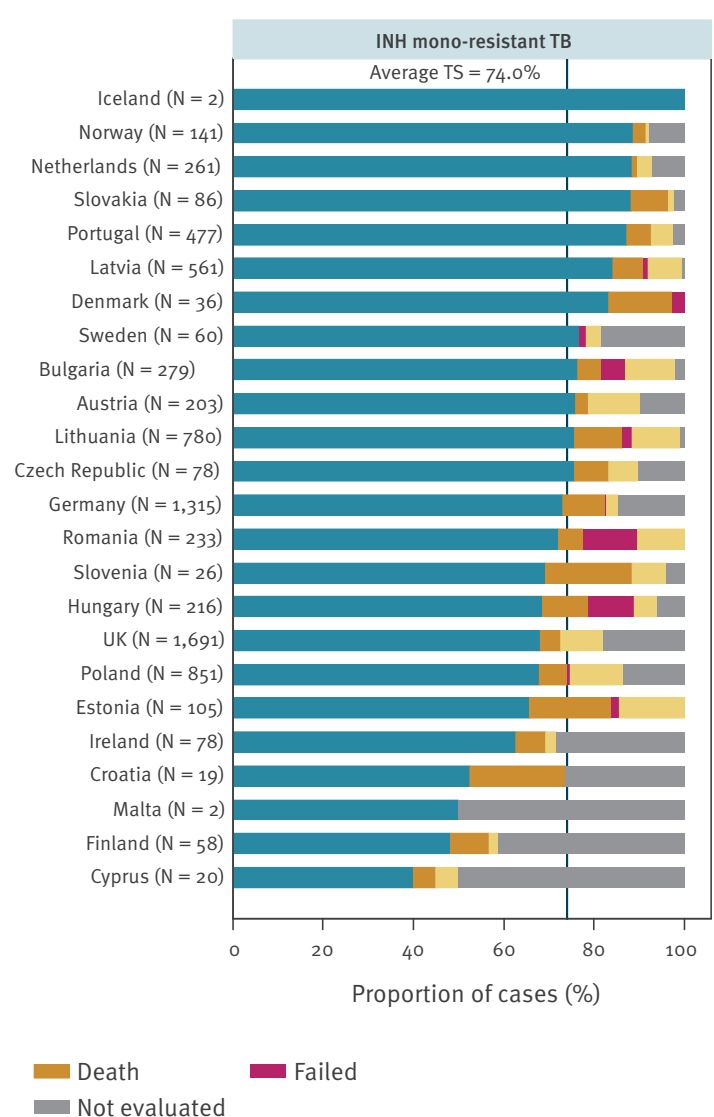

EU/EEA: European Union/European Economic Area; INH: isoniazid; TB: tuberculosis; TESSy: the European Surveillance System; TS: treatment success; UK: United Kingdom.

a Information missing for 67 cases.

Data source: TESSy. 


\section{FIGURE 4}

Factors associated with unsuccessful treatment among cases with isoniazid mono-resistant tuberculosis, EU/EEA, 2002$2014(\mathrm{n}=7,578)$

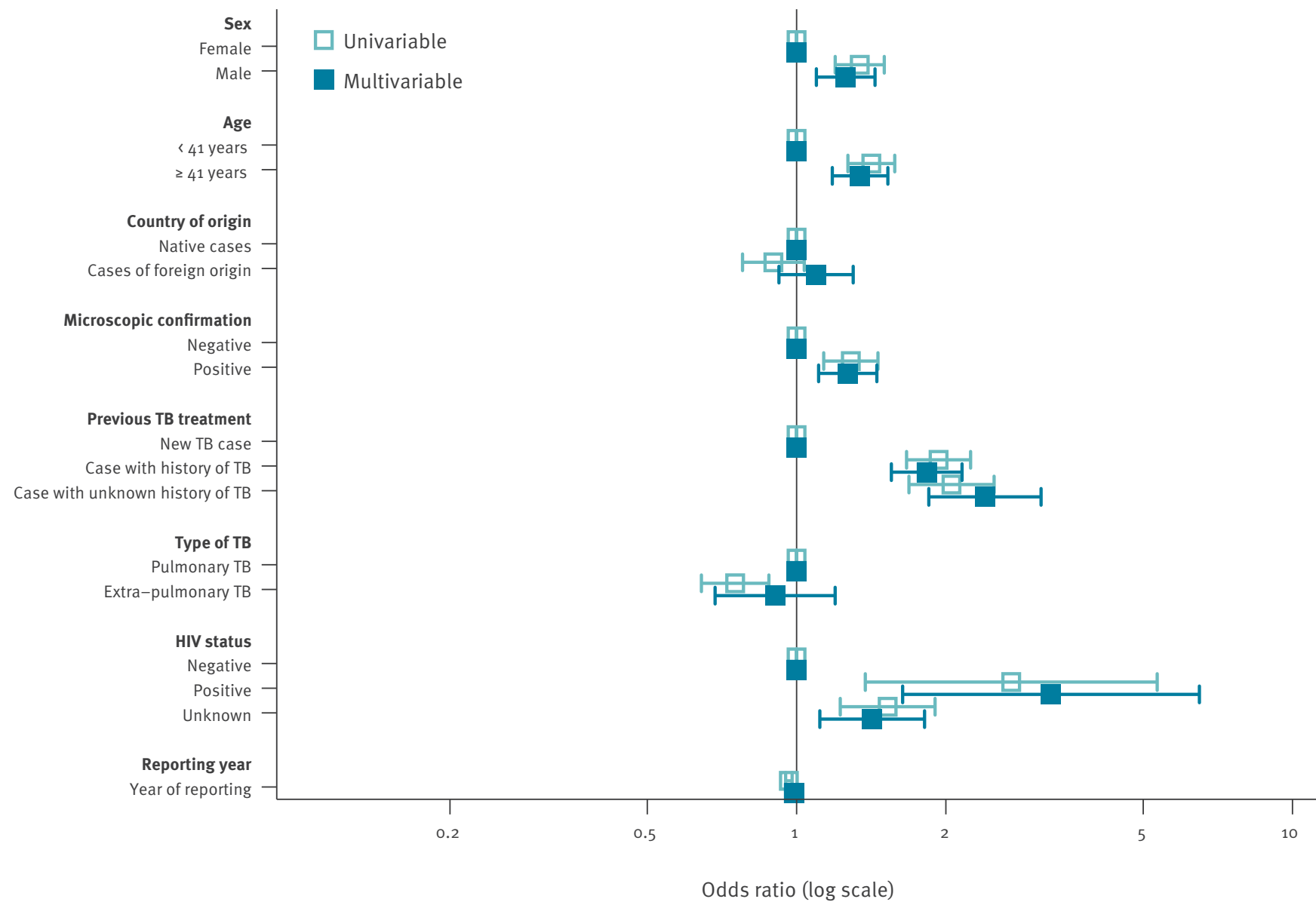

$\mathrm{Cl}$ : confidence interval; EU/EEA: European Union/European Economic Area; INH: Isoniazid; TB: tuberculosis; TESSy: the European Surveillance System.

Univariable and multivariable analyses were based on multilevel logistic regression models corrected for clustering within countries using an unstructured covariance matrix. TB cases with available information for all predicting factors were included in the multivariable analysis $(n=5,759 / 7,578)$. Excluded cases have a slightly higher treatment success $(74.7 \%$ vs $73.8 \% ; p$ value $=0.46)$.

Data source: TESSy.

before the year 2000 and were mainly conducted in countries in Asia and Africa. The same applies to the reviews evaluating treatment regimens for $\mathrm{INH}$ monoresistant TB that were published in 2016 [16] and 2017 [8], respectively. Therefore, our analysis of more recent 2002-14 EU/EEA surveillance data represents an addition to the currently available evidence.

Studies of TB treatment outcome under routine programmatic conditions have shown inconsistent results regarding treatment outcome of $\mathrm{INH}$ mono-resistant TB. While studies from the US [10], Denmark [12] and Israel [21] reported treatment outcome for INH monoresistant TB as excellent, highly successful or similar to drug-susceptible TB, studies from Peru [22], Mexico [23], Georgia [24] and South Africa [11] showed poorer treatment outcome compared with fully susceptible TB. Possible explanations might be differences in the included patient populations; for example, regarding HIV prevalence $[11,12]$, the availability of resources for patients, the accessibility of healthcare systems or the use of different treatment regimens. Our study, which pools data from 24 low HIV-prevalence and predominantly high-income European countries, shows that INH mono-resistance negatively affects treatment outcome. The study findings also highlight the need for timely identification of patients with INH mono-resistant $T B$, especially as rapid testing in recent years has focused more on the detection of RIF resistance as a proxy for MDR TB [6]. 
Comparison of studies has been hampered by different definitions used for INH mono-resistance. While many studies retained all $\mathrm{INH}$ resistance profiles, provided that RIF resistance and therefore MDR TB was excluded $[8,16]$, other studies required additional documented susceptibility for STR and EMB [23] or analysed INH mono-resistant and INH poly-resistant cases with additional resistance to STR or EMB separately [12]. To avoid misclassification, we have used the stricter definition requiring documented DST results for INH, RIF, STR and EMB for all cases. However, while gaining specificity in the definition of INH mono-resistance, this approach has resulted in the loss of a large number of cases for which these susceptibility testing results were not available, with considerable differences in the percentages of cases that could be included by country.

The finding that EU/EEA countries have different proportions of patients with INH mono-resistant TB still under treatment at 12 months might be a surveillance artefact related to variation in reporting procedures or the result of the use of different treatment regimens with different durations, reflecting the current lack of an agreed standard regimen for the treatment of INH mono-resistant TB cases $[18,25,26]$. As the 12-month outcome therefore did not seem to be the most adequate endpoint for analysis of the treatment outcome of INH mono-resistant TB, we chose a composite outcome for this study using the final documented outcome irrespective of the time to reporting (12 months, 24 months or 36 months after the start of treatment).

The factors found to be associated with a higher risk of unsuccessful treatment outcome in INH mono-resistant TB in this study-higher age, male sex, positive microscopy, positive HIV status-have been described before as associated with unsuccessful TB treatment outcome independent of drug resistance status [27,28]. Prior TB treatment has also been reported as a risk factor for unsuccessful outcome in patients with INH monoresistant TB [29]. In our study, these factors influenced TB treatment outcome regardless of the presence or absence of INH mono-resistance, indicating that they are not specific to INH mono-resistant TB, but rather are associated with lower TB treatment success in general.

The strengths of our study are the inclusion of a large number of cases and the application of a multilevel model to correct for TB clustering. This allowed to control for possible selection bias related to reporting countries and for unobserved heterogeneity between countries, thereby enhancing the generalisability of our findings. However, there are also several limitations to our study, mainly related to the use of surveillance data collected with the aim to inform TB programme management and not to evaluate clinical outcomes. As a result, data on the severity of TB disease, underlying diseases and treatment regimens were not available.
In addition, information on DST for PZA is not available in the TESSy data. In a sensitivity analysis using German notification data $(40,063$ TB cases, of which 1,310 were INH mono-resistant) that include information on DST for PZA, cases resistant to PZA were more frequent among INH mono-resistant TB compared with otherwise fully susceptible TB cases (5.4\% vs $1.8 \%$; $\mathrm{p}<0.01)$. However, no impact of the PZA resistance status on the relationship between INH mono-resistant TB and treatment success was observed (adjusted OR: $0.8 ; 95 \% \mathrm{Cl}: 0.6-1.4 ; \mathrm{p}=0.77$ ). Another limitation related to DST is that no information is available on the level of INH-resistance and the type of INH resistance mutations involved, which have been shown to influence treatment outcome [30].

Lastly, our study included data from only 24 of 31 EU/EEA countries; cases from seven countries were excluded due to lack of reporting treatment outcome or case-based susceptibility data (Table 1). Therefore, our data pertain only to these 24 EU/EEA countries and cannot be generalised to the whole EU/EEA without caution. Of note, $80.7 \%$ of reported cases had to be excluded due to missing information. As systematic reasons for lack of reporting within the 24 countries with included cases are not known, it is not possible for us to hypothesise how this might have affected our findings.

In conclusion, this study shows that treatment of patients with INH mono-resistant TB under routine programme conditions leads to lower treatment success compared with fully susceptible TB. The association of INH mono-resistance with negative treatment outcome highlights the need to pay increased attention to the timely identification and management of these cases to ensure treatment success for individual patients, as well as to reduce the risk for further resistance development on a population level.

\section{Acknowledgements}

The authors would like to thank Dr André Charlett, Head, Statistics, Modelling and Economics Dept. at Public Health England for advice on the statistical analysis.

The authors acknowledge the nominated national operational contact points for tuberculosis: Peter Henrik Andersen, Trude Margrete Arnesen, Bernhard Benka, Thorsteinn Blondal, Colin Campbell, Domnica Ioana Chiotan, Edita Davidavičienè, Raquel Duarte, Lena Fiebig, Jean-Paul Guthmann, Jerker Jonsson, Ourania Kalkouni, Maria Koliou, Maria Korzeniewska-Kosela (http://orcid.org/o0oo-00017693-9012), Gábor Kovács, Francesco Paolo Maraglino, Dace Mihalovska, Joan O'Donnell, Analita Pace Asciak, Laura Sanchez-Cambronero Cejudo, Aleksandar Simunovic, Erika Slump, Hanna Soini, Ivan Solovič, Petra Svetina, Lucy Thomas, Tonka Varleva, Piret Viiklepp, Jiří Wallenfels, Maryse Wanlin and Pierre Weicherding (names in alphabetical order) for providing the surveillance data used in this analysis. 


\section{Conflict of interest}

None declared.

\section{Authors' contributions}

Basel Karo, Anke Kohlenberg, Lena Fiebig, Vahur Hollo, Sarah Jackson, Cathriona Kearns, Csaba Ködmön, Marieke van der Werf: development of the analysis protocol for this study;

\section{Basel Karo: statistical analysis;}

Basel Karo, Anke Kohlenberg, Marieke van der Werf: drafting of manuscript;

Basel Karo, Anke Kohlenberg, Vahur Hollo, Raquel Duarte, Lena Fiebig, Sarah Jackson, Cathriona Kearns, Csaba Ködmön, Maria Korzeniewska-Kosela, Dimitrios Papaventsis, Ivan Solovic, Dick van Soolingen, Marieke J. van der Werf: critical revision of the manuscript for important intellectual content.

\section{References}

1. World Health Organization (WHO). Global Tuberculosis Report 2017. Geneva: WHO; 2017. Available from: http://www.who.int/ tb/publications/global report/en/

2. Hollo V, Beauté J, Ködmön C, van der Werf MJ. Tuberculosis notification rate decreases faster in residents of native origin than in residents of foreign origin in the EU/EEA, 2010 to 2015. Euro Surveill. 2017;22(12):30486. https://doi. org/10.2807/1560-7917.ES.2017.22.12.30486 PMID: 28367798

3. European Centre for Disease Prevention and Control (ECDC) / WHO Regional Office for Europe (WHO/Europe). Tuberculosis surveillance and monitoring in Europe 2017. Stockholm: ECDC; 2017. Available from: https://ecdc.europa.eu/sites/portal/ files/media/en/publications/Publications/ecdc-tuberculosissurveillance-monitoring-Europe-2017.pdf

4. van der Werf MJ, Ködmön C, Hollo V, Sandgren A, Zucs P. Drug resistance among tuberculosis cases in the European Union and European Economic Area, 2007 to 2012. Euro Surveill. 2014;19(10):20733. https://doi.org/10.2807/1560-7917. ES2014.19.10.20733 PMID: 24650865

5. Mitchison DA. Role of individual drugs in the chemotherapy of tuberculosis. Int J Tuberc Lung Dis. 2000;4(9):796-806. PMID: 10985648

6. Stagg HR, Lipman MC, McHugh TD, Jenkins HE. Isoniazidresistant tuberculosis: a cause for concern? Int J Tuberc Lung Dis. 2017;21(2):129-39. https://doi.org/10.5588/ijtld.16.0716 PMID: 28234075

7. Jenkins HE, Zignol M, Cohen T. Quantifying the burden and trends of isoniazid resistant tuberculosis, 1994-2009. PLoS One. 2011;6(7):e22927. https://doi.org/10.1371/journal. pone.0022927 PMID: 21829557

8. Gegia M, Winters N, Benedetti A, van Soolingen D, Menzies D. Treatment of isoniazid-resistant tuberculosis with firstline drugs: a systematic review and meta-analysis. Lancet Infect Dis. 2017;17(2):223-34. https://doi.org/10.1016/S14733099(16)30407-8 PMID: 27865891

9. Law S, Benedetti A, Oxlade O, Schwartzman K, Menzies D. Comparing cost-effectiveness of standardised tuberculosis treatments given varying drug resistance. Eur Respir J. 2014;43(2):566-81. https://doi. org/10.1183/09031936.00005613 PMID: 23766335

10. Cattamanchi A, Dantes RB, Metcalfe JZ, Jarlsberg LG, Grinsdale J, Kawamura LM, et al. Clinical characteristics and treatment outcomes of patients with isoniazid-monoresistant tuberculosis. Clin Infect Dis. 2009;48(2):179-85. https://doi. org/10.1086/595689 PMID: 19086909

11. Jacobson KR, Theron D, Victor TC, Streicher EM, Warren RM, Murray MB. Treatment outcomes of isoniazid-resistant tuberculosis patients, Western Cape Province, South Africa. Clin Infect Dis. 2011;53(4):369-72. https://doi.org/10.1093/cid/ cir406 PMID: 21810750

12. Bang D, Andersen PH, Andersen AB, Thomsen VO. Isoniazidresistant tuberculosis in Denmark: mutations, transmission and treatment outcome. J Infect. 2010;60(6):452-7. https://doi. org/10.1016/j.jinf.2010.03.017 PMID: 20347869
13. Garcia-Prats AJ, du Plessis L, Draper HR, Burger A, Seddon JA, Zimri K, et al. Outcome of culture-confirmed isoniazid-resistant rifampicin-susceptible tuberculosis in children. Int J Tuberc Lung Dis. 2016;20(11):1469-76. https://doi.org/10.5588/ ijtld.16.0293 PMID: 27776587

14. Yuen CM, Jenkins HE, Rodriguez CA, Keshavjee S, Becerra MC. Global and Regional Burden of Isoniazid-Resistant Tuberculosis. Pediatrics. 2015;136(1):e50-9. https://doi. org/10.1542/peds.2015-0172 PMID: 26034243

15. Karo B, Krause G, Hollo V, van der Werf MJ, Castell S, Hamouda 0 , et al. Impact of HIV infection on treatment outcome of tuberculosis in Europe. AIDS. 2016;30(7):1089-98. https://doi. org/10.1097/QAD.0000000000001016 PMID: 26752278

16. Stagg HR, Harris RJ, Hatherell HA, Obach D, Zhao H, Tsuchiya $\mathrm{N}$, et al. What are the most efficacious treatment regimens for isoniazid-resistant tuberculosis? A systematic review and network meta-analysis. Thorax. 2016;71(10):940-9. https:// doi.org/10.1136/thoraxjnl-2015-208262 PMID: 27298314

17. Fregonese F, Ahuja SD, Akkerman OW, Arakaki-Sanchez D, Ayakaka I, Baghaei P, et al. Comparison of different treatments for isoniazid-resistant tuberculosis: an individual patient data meta-analysis. Lancet Respir Med. 2018;6(4):265-75. https:// doi.org/10.1016/S2213-2600(18)30078-X PMID: 29595509

18. World Health Organization (WHO). WHO treatment guidelines for isoniazid-resistant tuberculosis - supplement to the WHO treatment guidelines for drug-resistant tuberculosis. Geneva: WHO; 2018. Available from: http://www.who.int/tb/ publications/2018/WHO_guidelines_isoniazid_resistant_TB/ en/

19. European Commission. Commission Regulation No 2119/98/ EC of 24 September 1998 on setting up a network for the epidemiological surveillance and control of communicable diseases in the Community. Official Journal of the European Union. Luxembourg: Publications Office of the European Union. 3.10.1998:L 268/1. Available from: https:// eur-lex.europa.eu/resource.html?uri=cellar:293fab95972a-4doc-ba28-45d9055fe1a3.0008.02/ DOC_1\&format=PDF

20. Menzies D, Benedetti A, Paydar A, Royce S, Madhukar P, Burman W, et al. Standardized treatment of active tuberculosis in patients with previous treatment and/or with monoresistance to isoniazid: a systematic review and meta-analysis. PLoS Med. 2009;6(9):e1000150. https://doi.org/10.1371/ journal.pmed.1000150 PMID: 20101802

21. Fox L, Kramer MR, Haim I, Priess R, Metvachuk A, Shitrit D. Comparison of isoniazid monoresistant tuberculosis with drugsusceptible tuberculosis and multidrug-resistant tuberculosis. Eur J Clin Microbiol Infect Dis. 2011;30(7):863-7. https://doi. org/10.1007/s10096-011-1167-4 PMID: 21431989

22. Villegas L, Otero L, Sterling TR, Huaman MA, Van der Stuyft P, Gotuzzo E, et al. Prevalence, Risk Factors, and Treatment Outcomes of Isoniazid- and Rifampicin-MonoResistant Pulmonary Tuberculosis in Lima, Peru. PLoS One. 2016;11(4):e0152933. https://doi.org/10.1371/journal. pone.0152933 PMID: 27045684

23. Báez-Saldaña R, Delgado-Sánchez G, García-García L, CruzHervert LP, Montesinos-Castillo M, Ferreyra-Reyes L, et al. Isoniazid Mono-Resistant Tuberculosis: Impact on Treatment Outcome and Survival of Pulmonary Tuberculosis Patients in Southern Mexico 1995-2010. PLoS One. 2016;11(12):e0168955. https://doi.org/10.1371/journal.pone.0168955 PMID: 28030600

24. Gegia M, Cohen T, Kalandadze I, Vashakidze L, Furin I. Outcomes among tuberculosis patients with isoniazid resistance in Georgia, 2007-2009. Int J Tuberc Lung Dis. 2012;16(6):812-6. https://doi.org/10.5588/ijtld.11.0637 PMID: 22507372

25. Blumberg HM, Burman WJ, Chaisson RE, Daley CL, Etkind SC, Friedman LN, et al. American Thoracic Society/Centers for Disease Control and Prevention/Infectious Diseases Society of America: treatment of tuberculosis. Am J Respir Crit Care Med. 2003;167(4):603-62. https://doi.org/10.1164/rccm.167.4.603 PMID: 12588714

26. National Institute for Health and Care Excellence (NICE). Tuberculosis. London: NICE. [Accessed 13 Nov 2018: ]. Available from: https://www.nice.org.uk/guidance/ng33/chapter/ Recommendations\#managing-active-tb-in-all-age-groups

27. Waitt CJ, Squire SB. A systematic review of risk factors for death in adults during and after tuberculosis treatment. Int J Tuberc Lung Dis. 2011;15(7):871-85. https://doi.org/10.5588/ ijtld.10.0352 PMID: 21496360

28. Karo B, Hauer B, Hollo V, van der Werf MJ, Fiebig L, Haas W. Tuberculosis treatment outcome in the European Union and European Economic Area: an analysis of surveillance data from 2002-2011. Euro Surveill. 2015;20(49):30087. https://doi. org/10.2807/1560-7917.ES.2015.20.49.30087 PMID: 26676247 
29. Wang TY, Lin SM, Shie SS, Chou PC, Huang CD, Chung FT, et al. Clinical characteristics and treatment outcomes of patients with low- and high-concentration isoniazid-monoresistant tuberculosis. PLoS One. 2014;9(1):e86316. https://doi. org/10.1371/journal.pone.0086316 PMID: 24466020

30. Huyen MN, Cobelens FG, Buu TN, Lan NT, Dung NH, Kremer K, et al. Epidemiology of isoniazid resistance mutations and their effect on tuberculosis treatment outcomes. Antimicrob Agents Chemother. 2013;57(8):3620-7. https://doi.org/10.1128/ AAC.00077-13 PMID: 23689727

31. Lönnroth K, Migliori GB, Abubakar I, D’Ambrosio

L, de Vries G, Diel R, et al. Towards tuberculosis

elimination: an action framework for low-incidence

countries. Eur Respir J. 2015;45(4):928-52. https://doi.

org/10.1183/09031936.00214014 PMID: 25792630

\section{License, supplementary material and copyright}

This is an open-access article distributed under the terms of the Creative Commons Attribution (CC BY 4.0) Licence. You may share and adapt the material, but must give appropriate credit to the source, provide a link to the licence and indicate if changes were made.

Any supplementary material referenced in the article can be found in the online version.

This article is copyright of the authors or their affiliated institutions, 2019. 